\title{
Exploration of a Collaborative Self-Directed Learning Model in Medical Education
}

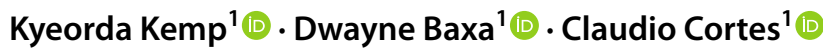

Accepted: 8 December 2021 / Published online: 4 January 2022

(c) The Author(s) under exclusive licence to International Association of Medical Science Educators 2021

\begin{abstract}
Purpose One of the aims of medical education is to generate lifelong learners, leading to the identification of self-directed learning (SDL) as an essential component of medical education. While SDL is focused on an individual learner, collaboration is critically important in medicine. We developed an online course using the collaborative SDL (CSDL) framework. A goal for the course was for students to gain a better appreciation for the SDL process by exploring the COVID-19 pandemic. Methods We utilized CSDL to implement a 2-week elective attended by fifteen M3 and M4 medical students. Students submitted short videos reflecting on their course experience and the relevance of the material to their future training. Qualitative analysis of reflections was conducted to determine the effectiveness of the CSDL framework, and an assessment of the course evaluations was performed to explore student perceptions of the course and its effectiveness at preparing them for practice. A survey regarding student perceptions of SDL was offered to M3 and M4 students in order to explore their experiences with SDL and perceptions of its importance in the context of the school curriculum.

Results The CSDL framework was effective in making students aware of the importance of SDL in medical practice. Students gained basic and clinical knowledge about the subject, experienced increased confidence, and appreciated collaborating with their peers. The survey offered to the general student body reflected that all students perceived that they employed SDL in their time as medical students. However, many students indicated that they had not utilized components of SDL beyond synthesizing and assessing their learning needs.

Conclusion CSDL is an effective method for promoting self-directed learning. Undergraduate medical course constructs utilizing CSDL will benefit students as they continue their career development.
\end{abstract}

Keywords Collaborative self-directed learning · Self-directed learning $\cdot$ COVID-19 · Online

\section{Introduction}

\section{Self-Directed Learning and Medical Education}

Lifelong learners must use effective self-directed learning (SDL) strategies to be successful [1-3]. SDL, as defined by Garrison [4], is an approach "where learners are motivated

Kyeorda Kemp

kyeordakemp@oakland.edu

Dwayne Baxa

baxa@oakland.edu

Claudio Cortes

cortes@oakland.edu

1 Department of Foundational Medical Studies, Oakland University William Beaumont School of Medicine, 586 Pioneer Dr, Rochester, MI 48309, USA to assume personal responsibility and collaborative control of the cognitive (self-monitoring) and contextual (selfmanagement) processes in constructing and confirming meaningful and worthwhile learning outcomes" (p. 18). In this learning method, the learner determines what knowledge they lack, their learning objectives, how to seek useful information, and whether they have met those objectives. While this is a learner-driven process, faculty and peers also play a crucial role in guiding and promoting the SDL by offering feedback [5]. In recent years, there has been a shift away from didactic lectures as a sole method of transferring knowledge to a student-centered approach to medical education where students take the initiative in their learning.

Physician knowledge declines with time [6] and evolves as science advances; therefore, medical students must gain the skills associated with lifelong learning. These skills must be developed early in their career and continuously practiced 
going forward as competing interests, and lack of access to instructors can create barriers to SDL development. The Liaison Committee on Medical Education (LCME), an accrediting body for medical schools in the USA and Canada, requires medical schools to provide opportunities for students to participate in SDL [7]. Moreover, SDL is required at the undergraduate medical education level and is incorporated in graduate medical education and continuing professional development $[8,9]$.

\section{Issues Defining and Implementing SDL in Medical Education}

While SDL is critical for medical education, there is no clear understanding of how to implement SDL or what counts as SDL. Problem- and case-based learning activities and flipped classroom exercises are often counted as SDL due to requiring students to perform independent research. However, these mechanisms should not be considered equivalent to SDL as they simply provide the environment for the practice of the SDL method. Critical components of SDL can be missing in these environments, as the goal setting is performed by faculty [8]. Also, students may not evaluate if their learning style was effective in meeting the goals. Teaching aspects of SDL out of sequence introduce an additional problem, as students may not connect the elements of SDL or be deficient in a particular aspect. Adding to this concern, many practicing physicians are not trained in SDL [8], compounding the urgency for students to develop skill sets associated with SDL and learn the importance and aspects of SDL before entry into graduate education. Ginzburg et al. [8] contend that "the personal and environmental characteristics necessary for identification and correction of deeper, more complex gaps in understanding" are incorporated in SDL and that SDL be seen as a "habit of practice." Moreover, they advocate for the development of research programs around SDL in medical education. Indeed, the Shapiro Institute for Education and Research and the Association of American Medical Colleges collaborated with eight medical schools from North America to address the challenge of defining, implementing, and evaluating SDL. They also explored ways to support it in health education, including research into pedagogy, and published their findings earlier this year [10].

SDL generated outside of medicine; therefore, implementation of SDL in medical education must be grounded in the circumstances unique to this field. SDL is a learnercentered education strategy where the learner's needs regarding breaches in knowledge are of foremost concern. Ricotta et al. [10] indicate that this can be at odds with the guiding principles of medicine, as clinical care for patients supersedes the needs of the learner. They propose four elements required for SDL in medicine: supportive institutional environment; student traits that promote SDL, assessment, and faculty development; and training in the pedagogy of SDL. All of these aspects are interconnected. For example, the environment must provide resources and support for SDL, reward curiosity and vulnerability, engage the learner in the educational process, model aspects of SDL, and find uncertainty acceptable. In turn, this will allow students the space to grow in the personal attributes identified by Ricotta et al. [10] as being necessary for SDL, for example curiosity, mindfulness, flexibility, and metacognition, among others. Faculty must be trained in self-directed learning, practice the skills associated with it in their lives, be trained in how to give timely and effective feedback, prioritize learning strategies that promote learner engagement, and be encouraged to engage in the pedagogy around SDL to inform their own teaching practices. While Ricotta et al. [10] acknowledge that assessment of SDL is difficult due to an absence of a validated assessment tool, they identify a number of recommendations for assessing SDL. They state that assessments should be holistic, multi-faceted, and longitudinal with checkpoints, and that feedback should be provided on the process and student outcomes and should incorporate the student's thought process and motivation in order to isolate the skills associated with identifying information from motivation and the cognitive processes needed to be a selfdirected learner.

\section{Collaborative Self-Directed Learning Model and Promoting the Goals of SDL in Medical Education}

SDL has been subject to criticism due to its focus on the individual learner and promotion of the success of the individual as opposed to the collective [11]. SDL is the primary method employed in problem-based learning activities where students have independent control and responsibility for their tasks [12]. In the study of medicine, while it is crucial that individuals learn how to identify and assess deficits, students must also learn how to work within teams as a community of practice to solve larger problems and meet the needs of society, as is required of medical professionals. Collaborative learning, where students work in groups to promote each other's learning, lends itself to developing these crucial skills. Collaborative learning and group cohesion appear to support SDL readiness [13-15], and educators have created opportunities within SDL for collaboration and teamwork [16, 17]. Indeed, working in small groups appeared to promote SDL behaviors in mixed teams of first-year medical students and biomedical science graduate students [18]. Moore et al. [19] expand this by creating the collaborative self-directed learning (CSDL) framework that allows students to practice real-life approaches to problem-solving. Moore et al. [19] explain that learners can 
work independently on learning objectives but collaborate with others to critique and reflect on discoveries and share viewpoints and knowledge.

We utilized the CSDL framework to help prepare our students for practicing medicine. Students experienced a guided approach to work with a team to develop informational resources they felt would fill self-identified knowledge gaps for themselves and their peers in a currently emerging infectious disease situation. This paper briefly discusses the process by which we created the course and how CSDL was incorporated in the course, but focuses on exploring student perceptions of SDL in the course using student reflections and course evaluations. The goals of this observational study were as follows:

1. Determine if students find SDL as employed in the course effective for their learning

2. Assess how students at our institution perceive SDL in the curriculum

With this information, we explored where further opportunities for CSDL and SDL can be developed in medical school curricula to prepare students for their future careers.

\section{Methods}

\section{Course Design and Setting}

Oakland University William Beaumont School of Medicine (OUWB) is a private allopathic medical school located on the campus of Oakland University, Rochester, Michigan. There are approximately 125 matriculating undergraduate medical students in each cohort. The curriculum integrates basic and clinical sciences throughout 4 years of education. In the clinical years, students also pursue required medical or basic science-related research projects and longitudinal courses on clinical bioethics, medical humanities, and the art and practice of medicine. The majority of the courses before the pandemic were held face-to-face but moved online in March of 2020 and for the 2020-2021 academic year.

This course was developed by basic science faculty to be modeled as a Master's level graduate seminar course exploring the topic of SARS-CoV-2. The course was held over 9 days, meeting approximately $3 \mathrm{~h}$ per day in a virtual format. The first week consisted of the course introduction and format instructions, journal clubs, independent time dedicated for group goal setting, research, presentation preparation, and student meetings with course instructors for feedback (Fig. 1). The second week consisted of student presentations, peer questions and feedback, faculty review, presentation revisions, and student reflections of their experience.

Students employed backward design from an instruction prompt to identify what information they believed would be needed as new physicians to serve their patients. Students were required to produce presentations that would become instructional resources. These presentation products were incorporated into a virtual resource about the virus and COVID-19 that was shared with the wider OUWB and Oakland University (OU) communities. A goal for the course was for students to gain a better appreciation for the SDL process using a current health issue. To this end, the course was initiated with a didactic lesson conveying the definition, principles, and practice of SDL so that students would understand both the intent of the course and the process for

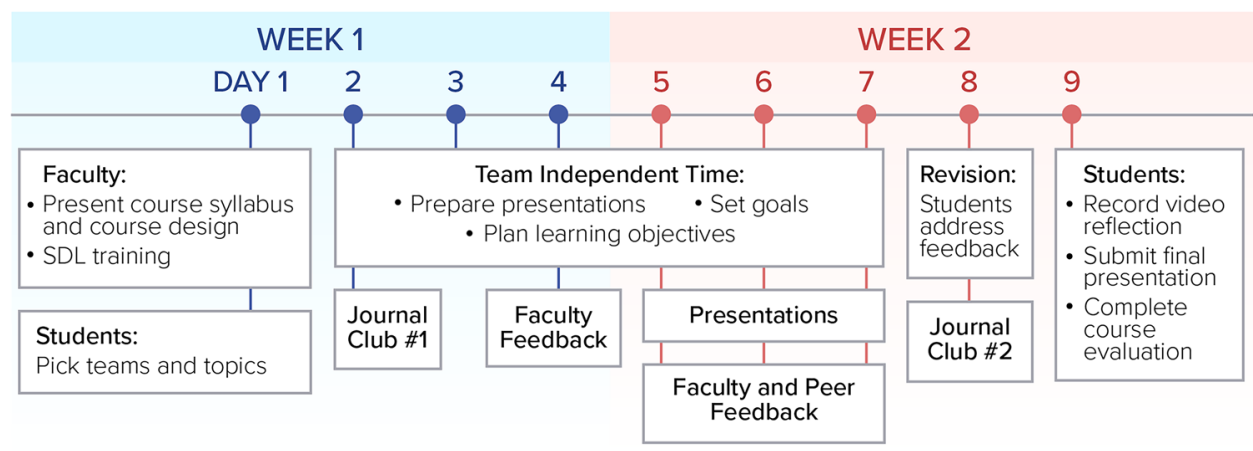

Fig. 1 Outline for the course structure. The sequence of events for overall self-directed learning delivery and the general format of the educational sessions are outlined. The sequence of events occurred in 2 weeks. Week 1: Day 1 includes the presentation of the course syllabus and course design, the self-directed learning training, and the assigned teams and general course assignments. Day 2 includes a faculty-led journal club. Days 2 through 7 include the teamindependent time to set goals and plan learning objectives and to prepare a PowerPoint presentation. In day 4, students received feedback from faculty members about their work. Week 2 : In days 5 through 7, the team presented their work to peers and faculty members and feedback was provided by both faculty members and peers. Day 8 includes a faculty-led journal club and time for students to address the feedback provided the days before. Day 9 includes a video-recording reflection, submission of final presentation, and survey for course evaluation 
developing their work products. An overall logistical framework of the online course is provided in Fig. 1.

\section{Participants}

Participants were M3 (11) and M4 (4) year undergraduate medical students at OUWB enrolled in the winter elective course COVID-19/Pandemic. Students could enroll in this elective as one of several options to satisfy graduation credit requirements after previous course scheduling during the clerkship years was impacted by the inability to offer some in-person courses. Course enrollment was capped at twenty students. Medical students were self-divided into teams of three to four based on their topic interest.

\section{Course Objectives}

The course objectives and how they were assessed are found in the syllabus (Online Resource 1, pages 6-7). The students were informed that they would use their group presentations to create a resource that would be available to educate their peers, both in the course and across the institution. The course was divided into two sections, with a week dedicated to preparation and a week devoted to peer teaching. Details regarding the course structure can be found in Fig. 1 and Online Resource 1.

\section{Preparation for Peer Teaching}

During the preparation phase, students were asked to assign themselves into teams to explore the main topics listed in Table 1. The broad course topic choices were developed by faculty with the aim of being relevant to any emerging infectious disease issue. Example subtopics were offered, but students were encouraged to pursue any topic they believed to be of importance to a medical student or resident in order to practice in the face of the COVID-19 pandemic. The student-selected subtopics are listed in Table 1 . Students were then given time for teams to prepare presentations on these topics to teach their peers (Fig. 1). Students self-managed their individual assignments within their group in fulfillment of

Table 1 Topics explored in the course

\begin{tabular}{|c|c|c|}
\hline Topic choices & Student selected subtopics & Student developed learning objectives \\
\hline Identifying an emerging disease & $\begin{array}{l}\text { Discovering the etiology } \\
\text { Pathophysiology of COVID-19 } \\
\text { Developing a case definition for differential diagnosis } \\
\text { Surveillance vs. diagnostic testing } \\
\text { Current research into testing }\end{array}$ & $\begin{array}{l}\text { Explain the pathophysiology of COVID-19 } \\
\text { Identify the clinical features of COVID-19 } \\
\text { Recognize the diagnosing criteria }\end{array}$ \\
\hline Defining an outbreak & $\begin{array}{l}\text { Epidemiology of a pandemic } \\
\text { History of SARS-lessons from the past and present } \\
\text { Comparing the pandemics of other diseases }\end{array}$ & $\begin{array}{l}\text { Identify why COVID-19 has been so successful } \\
\text { Explore how various countries have responded to } \\
\text { COVID-19 and their success } \\
\text { Analyze other pandemics and epidemics and compare } \\
\text { them to the current COVID-19 pandemic in terms of } \\
\text { infectiousness and response }\end{array}$ \\
\hline Treatment & $\begin{array}{l}\text { The process of finding treatments: new vs. off-the- } \\
\text { shelf } \\
\text { Exploring current research into treatments }\end{array}$ & $\begin{array}{l}\text { Explore current research into treatments, testing, and } \\
\text { vaccines } \\
\text { Gain familiarity with the management of care for } \\
\text { patients infected with SARS-CoV-2 } \\
\text { Reflect upon the ethics of decision making regarding } \\
\text { who gets treatment }\end{array}$ \\
\hline Prevention & $\begin{array}{l}\text { Comparing strategies to control the spread of } \\
\text { COVID-19 } \\
\text { Exploring current research into vaccines }\end{array}$ & $\begin{array}{l}\text { Explore current suggestions to prevent the spread } \\
\text { Compare responses in other countries and see what has } \\
\text { worked } \\
\text { Describe the proper use and care of personal protective } \\
\text { equipment during a pandemic } \\
\text { Explore potential issues with vaccines looking at coro- } \\
\text { naviruses and immunity }\end{array}$ \\
\hline A community at risk & $\begin{array}{l}\text { Communication with your patients } \\
\text { Exploring the social impacts of COVID-19 (eco- } \\
\text { nomic, social, etc.) } \\
\text { Myths and conspiracy theories and how to respond } \\
\text { Current issues facing physicians and other health } \\
\text { professionals in the USA }\end{array}$ & $\begin{array}{l}\text { Explore the social impacts of COVID-19 (economic, } \\
\text { social, etc.) } \\
\text { Identify ways to communicate about COVID-19 with } \\
\text { peers, patients, and the public } \\
\text { Identify risk to health professionals } \\
\text { Learn about how to detect fact vs. fiction }\end{array}$ \\
\hline
\end{tabular}

Students developed their own learning objectives from topics and subtopics provided in the course. Column 1 shows the course topic choices. Column 2 shows students' selected subtopics explored in their presentation. Students' developed learning objectives can be found in column 3 
group-developed learning objectives for their presentations. Students met with the instructors to discuss their topic selections, learning objectives, resource selections, progress, and concerns on day 4 of the course. Real-time feedback was given by course instructors via video conference to each group to assist students in making any necessary adjustments relative to their self-identified objectives.

\section{Peer Teaching}

Students presented their topic information in the second week during sessions that met virtually for 2 to $3 \mathrm{~h}$ per day. There were two presentations per day, except for the first day. Class discussion followed each presentation, and students were required to give feedback anonymously to each other regarding their presentations which were used to revise their work according to an evaluation rubric adapted from Purdue University [20]. Students also met with the course directors and received feedback regarding their work products. Feedback was then incorporated to produce the final presentation product prior to the end of the course. Due to the general campus community's need to become educated about COVID-19, the presentations were then placed in an online resource that could be accessed internally by all faculty, staff, and students at OU via a cloud-based maintenance software, eSpace. This format was chosen due to the research indicating that self-directed e-learning modules can effectively increase learners' knowledge before entry into clinical rotations [21]. As of March 2021, 74 individuals have accessed the online platform.

\section{Incorporation and Assessment of Self-Directed Learning}

The importance and purpose of SDL were addressed on the first day of the course, as previous educators have highlighted students must be informed about the significance of SDL in their education and future practice to improve acceptance [22]. Students were asked about their understanding of SDL. We briefly explained why SDL is critical for practicing physicians and then discussed the aspects of SDL. We next explained how SDL was assessed in the course following measures outlined by the LCME [7].

While the LCME does not require self-reflection in SDL, it is a critical self-directed learning component [19, 23]. Therefore, all students were required to complete a 3- to 5-min video log reflecting on what they learned regarding COVID-19 and SDL use. They were given the prompt: what have you learned, how will you use this moving forward, and how will you continue to use SDL in your practice? The information for how SDL was assessed in relation to LCME and SDL requirements can be found in Table 2.

\section{Data Collection and Analysis}

\section{Data Collected}

Course Evaluations Fifteen student course evaluations were analyzed to determine how the students perceived/ experienced the COVID-19/Pandemic course. The standard OUWB course evaluation was composed of nine questions on a 5-point Likert scale. Six of the questions focused on student satisfaction with the course content, structure, and

Table 2 Assessment of SDL components in the course. Several components of SDL were identified that were assessed in the course

\begin{tabular}{|c|c|}
\hline Component & How it was assessed in the course \\
\hline \multirow{2}{*}{$\begin{array}{l}\text { Identify, analyze, and synthesize information relevant to } \\
\text { their learning needs* }{ }^{\wedge}\end{array}$} & Students selected their groups \\
\hline & $\begin{array}{l}\text { Students identified knowledge gaps and relevant information they felt medical students } \\
\text { should know relative to pandemics and, specifically, COVID-19 }\end{array}$ \\
\hline Assess the credibility of information sources ${ }^{\mathrm{a}, \mathrm{b}}$ & Students searched the literature and vetted sources to integrate into their presentations \\
\hline \multirow[t]{2}{*}{ Share the information with their peers and supervisors ${ }^{\mathrm{a}, \mathrm{b}}$} & Students prepared presentations based on self-defined objectives \\
\hline & Students presented information to peers, guest experts, and course directors \\
\hline \multirow[t]{2}{*}{ Receive feedback on their information-seeking skills $s^{\mathrm{a}, \mathrm{b}}$} & $\begin{array}{l}\text { Course directors assessed the credibility of sources collated and information collected } \\
\text { and synthesized by students at the week } 1 \text { check-in and via the student presentations }\end{array}$ \\
\hline & $\begin{array}{l}\text { Students presented to the class and received peer and faculty feedback to incorporate } \\
\text { into presentation revisions in order to refine the materials that would be embedded } \\
\text { into the final COVID-19 online resource }\end{array}$ \\
\hline $\begin{array}{l}\text { Reflect on what they learned and the use and importance } \\
\text { of SDL in their learning }{ }^{\mathrm{b}}\end{array}$ & Students complete a self-reflection video log \\
\hline
\end{tabular}

${ }^{a}$ Defined by LCME as SDL

${ }^{\mathrm{b}}$ Supported by the literature 
objectives. The option choices were poor, fair, good, very good, and excellent. Three of the questions were focused on the effectiveness of the course with regard to preparation for entering the clinic during the time of the pandemic and SDL. The options were strongly disagree, disagree, neutral, agree, and strongly agree. The two open-response questions asked what the course did well and what could be improved.

Self-Reflective Video A single reflection video was recorded by each student using the YouSeeU platform as part of the course and was used for qualitative analysis.

\section{Qualitative Analysis of Student Video Reflections}

The student reflection videos were transcribed, and a thematic analysis was conducted using a grounded theory approach to identify themes [24]. Below, we briefly outline this process.

Codebook Development Three individuals reviewed five of the videos separately and identified themes and potential codes (KK, DB, and CC). The researchers met and discussed the themes and the evidence that supported the themes and possible codes. The researchers organized the codes identified individually under themes. Codes that were deemed redundant were combined into a single code. The researchers then did a round of review of all fifteen of the transcripts and met as a group to further refine the codes that fit underneath these themes. The researchers met again to discuss how the transcripts were coded.

Coding Coders continued to meet throughout the process to reconcile and revise the codebook as necessary. Once $100 \%$ agreement was reached on the codebook, the three researchers independently coded the transcripts using the codebook. Transcripts were uploaded into NVivo (release 1.3.2) and coded (KK). Two of the researchers (KK and DB) met again to confirm that the final coding of the transcripts was agreed upon. The rate of agreement was $94.5 \%$ across all transcripts. The two researchers resolved disputed transcripts, so the final agreement was $100 \%$.

\section{Survey About Student Experiences with Self-Directed Learning at Our Institution}

All current M3 and M4 students and the four 2020 M4 students that took the course were invited to complete a survey about their experiences with SDL in courses at OUWB from December of 2020 to February of 2021. The survey was constructed in the Qualtrics survey instrument and was delivered electronically via the school listserv. The questions are found in Online Resource 2.

\section{Results}

\section{Results of the Course Evaluations}

Student satisfaction with the course (nine questions) was measured on a 5 -point Likert scale $(1=$ poor, $5=$ excellent, or $1=$ strongly disagree, $5=$ strongly agree). The course evaluation indicated that the course was well received by the students; students enjoyed the structure and content of the course, with over $93 \%$ of students rating the course as good or above with regard to these areas (Online Resource 3). The percentage of students who responded well to excellent ranged from 93 to $100 \%$ for questions related to assessments well aligned with objectives (93\%), quality of feedback (93\%), clarity of learning objectives (93\%), and opportunities for active engagement in learning (93\%). The percentage of students who responded agree and strongly agree was $100 \%$ for questions related to whether the course furthered the understanding of self-directed learning, was beneficial for their future practice, helped them prepare to educate others about COVID-19, and if they would recommend this course to other students (Online Resource 3).

One concept that emerged upon analysis of the free responses for the course evaluations was that students seemed pleased with the course. This finding bolstered the results from the Likert scale section. Moreover, students felt that the course prepared them for their future practice, and they felt the course furthered their understanding of SDL. Students wrote:

[T] he course provided a great opportunity for selfdirected research and learning in the midst of an actively changing body of knowledge. I enjoyed finding new sources of information and becoming more comfortable with maneuvering government-issued information, such as that from the Center for Disease Control and Prevention (CDC) and WHO.

[T] he course was beneficial to take a deep dive into the literature on COVID especially given that I am entering practice soon. It also was a great example of self-directed learning, which will be applicable for the rest of my career.

Students also seemed to appreciate the flexibility of the faculty, the feedback and guidance that the students received, that the course was self-directed, and that they had the opportunity to do presentations. One student wrote:

This was a really well-done course. The course directors understood what SELF-DIRECTED learning meant and allowed students to take initiative themselves in choosing their topic and preparing the presentation. They also provided a lot of feedback for us before the final presentation. This is what I'd expect a good self-directed graduate course to look like. I'm 
surprised they pulled this together and executed it so well on such short notice- great job.

Two concepts emerged when students were asked what could be done to improve the course. Students wished they had more opportunities for discussion, that the journal clubs were student-led, and that more time was allotted for additional journal discussion. We chose to make the journal clubs instructor-led because we were concerned about overtaxing the students. However, the student feedback made it clear that they desire more, not less, responsibility regarding the course. A student wrote:

I would have enjoyed having more opportunities for open forum discussions with my fellow students. This is particularly true during journal club discussion days. It would be nice to have more journal articles to discuss together!

There were also two students that mentioned they would have preferred more lectures and the ability to take on a "passive role."

\section{Thematic Analysis of the Student Reflection Videos}

Five themes emerged upon examination of the video reflections. These are outlined in Table 3 with the codes that nest under them.

\section{Awareness}

Fourteen out of the fifteen students acknowledged some sort of awareness, with the most prominent two being the importance of SDL in their practice and misinformation (Table 3). Eighty-seven percent of students mentioned that they gained awareness of the importance of SDL in their practice, with many students identifying its importance multiple times in their reflection (Table 3). Indeed, this code has the most quotes attributed to it. One student said:

So, self-directed learning obviously is super important to medical providers, and something like coronavirus just shows how important it is. Medicine is always moving. There're new publications, new treatments, new findings coming out on a daily basis.

The student was able to identify the importance of SDL beyond the current pandemic and explain how it is essential for staying up-to-date with the medical field. Another student illustrated this in two sections of their transcript:

You know we talked about the active learning, the self-directed learning, this is what the rest of my career is going to be, the rest of our careers for us that are going into residency in the coming months... [this] really was a great exercise in taking scientific literature, boiling it down to what matters to me as a
Table 3 Thematic analysis of student's reflections of SDL

\begin{tabular}{lcc}
\hline & Total of codes & Total number of transcripts \\
\hline Awareness & 28 & 13 \\
The importance of SDL in practice & 18 & 12 \\
Misinformation & 4 & 4 \\
Societal issues & 3 & 2 \\
Inadequacies in the health care system & 3 & 3 \\
Research processes & & \\
Knowledge & 23 & 11 \\
Identification of knowledge and tools for practice & 11 & 8 \\
Identification of general knowledge & & 5 \\
Appreciation & 9 & 5 \\
Collaboration & 7 & 2 \\
Communication & 4 & 1 \\
Teaching skills taught & 2 & 12 \\
Practice & & 2 \\
Environment & 17 & 5 \\
Enjoyed the course design & 2 & \\
Experienced feeling overwhelmed & & \\
Confidence & 9 & \\
Increased belief in self and abilities & & \\
\hline
\end{tabular}

Five main themes and their codes were identified from 15 student reflection transcripts. The total number of time codes was attributed to the transcripts that are offered in total. The number of student transcripts that contained a given code is represented in the table 
clinician and what matters to my patients and I think that again to have that as the last class in my four years of medical education, I can't think of a better way to conclude four years of increasingly selfdirected learning in a real-life, real-world example that's going to be ever-present and ever-pertinent in my practice in just a few short months.

The student not only identified that SDL is important for their career, but they understood that they were able to use it to identify information vital to their patients.

Eighty-seven percent of students had themes consistent with gaining awareness of misinformation, with many identifying it multiple times. The majority of students spoke about misinformation with regard to social media and how this fomented distrust. One student stated:

Just in general is how much controversy surrounds COVID-19, especially the ...conspiracy theories. I have found myself in a lot of conversations, especially about the $5 \mathrm{G}$ radiation.

Another student stated:

I also learned just in general about some of the misinformation and how widespread the misinformation is that a lot of our patients and family members and the public at large is receiving.

Another student went further and began exploring how this knowledge of misinformation will help them in their practice.

Also, in our personal lives to encourage ourselves, our family, our friends, our neighbors to be wellinformed and to understand how this virus spreads, how to prevent this virus from spreading, and also how to demystify the virus and get rid of some of the false narratives that exist right now ... So once again, I thought that was very helpful especially with all the questions swirling. It seems like every day we look in the media there's a different twist to the story. There's a lot of contradicting information, and God forbid you move from the media into social media because then it's just whatever somebody decided to type up. I think it was really helpful to understand this and to use it both for our own benefit, the benefit of those around us, and the benefit of our patients and our medical practice.

\section{Knowledge}

Eleven out of fifteen students identified a gain in knowledge, with most identifying knowledge and tools for practice multiple times. Students spoke directly about knowledge related to treatment and diagnosing. One student said:
Another thing I learned was about the patient presentation of somebody with COVID-19. Dr. [redacted] said that there's a lot of patients that come in who are very hypoxic but can talk to you and don't outwardly appear hypoxic on presentation. They might even have a good chest Xray and a good CT scan as well. So, I learned that you've got to be careful, and you can't assume that just because somebody doesn't look hypoxic on presentation or if they have a good scan, that those things mean they're not critical; you need to check their pulse ox.

Another student wrote:

I also learned a lot about the different treatments. I know now that everyone is saying hydroxychloroquine is the cure to COVID, but I know now that it's not, and it's like the best thing that we have.

Students also spoke about the tools needed to practice medicine:

...how to sift through it and find what was the most important to the information you were seeking. This could be done by staying up to date with journals, going to seminars, continuing medical education; all of those types of things in the future will be imperative to our practice, and this course was just a great reminder - especially with the speed at which information is coming out as to SARS-CoV-2.

\section{Appreciation}

Several students (five out of fifteen) expressed appreciation for collaboration. One student wrote:

So, I think that this course really helped me synthesize all of those really difficult concepts and things that would have taken me way too too long to investigate purely on my own but having classmates, M3s, and course directors to help direct me.

Here, the student is showing that they understand the importance of not only collaboration, but also the role others can play in their learning process. Indeed, students wrote:

...but seeing how much effort everyone put into their parts to break it down to one another and teach each other was a really valuable experience.

There's really no way for any of us to take as deep of a dive as we did collectively over the past two weeks on our own.

Students also expressed appreciation for communication (five out of fifteen) and how it could be used to educate family, friends, and patients.

I learned a lot about how to communicate with patients. 
They [patients] want their physicians to be able to relate to them, and definitely during a pandemic, sometimes physicians will have to say no, and there are reasons behind that. But, being able to explain that to patients and family members, it takes a different kind of communication skill to be able to do that and I think it's important to be able to know how to do that.

Students also expressed appreciation for teaching and their future practice.

\section{Course Environment}

As with the course evaluations, students overwhelmingly expressed that they enjoyed the course and the course environment (twelve out of fifteen). Students commented:

It had a great design. It motivated me and made me want to work. Which is great, because it's really easy not to work when you're at home.

I think this course was well run. I think that under the circumstances, we were able to learn a lot and were able to be independent in our learning.

So, I truly enjoyed the course, and I would like to thank each of the instructors for the time and effort they put into it. I know this course was put together quickly, so I know there was a lot of work on the front end, trying to get something of this caliber done in those few days. So, once again, thank you for all of your efforts.

One student expressed that the process was overwhelming, but they still found it valuable.

...being able to grasp all of this information in just a short matter of time in a few days was kinda overwhelming, but seeing how much effort everyone put into their parts to break it down to one another and teach each other was a really valuable experience.

\section{Confidence}

A subset of students (five out of fifteen) expressed increased belief in themselves and their abilities. Students said:

After this course, I am confident in my ability to use self-directed learning if another similar pandemic occurs or even for the normal research that occurs every day that is constantly being conducted and pushing out new information for the medical field and for people to learn.

This course also gave me a boost of confidence. I was in charge of explaining R0. And this is something that I straight up did not understand from the start of this whole thing, and everyone was saying flatten the curve. I'm like, okay. I'm just going to pretend I know what you're saying. Because I see these curves, and you're flattening them (student grimaces). And it just seemed so daunting to figure it out, but it only took me like half a day to be like 'Oh, this is what it is, and it's actually really simple to understand.' So, this course actually gave me the confidence that if I like to try to understand something, it'll be easier than I think.

\section{Results of the Survey on Self-Directed Learning at the Institution}

Of the 243 students that were eligible, 34 completed the survey. Their demographics and response rates can be found in Table 4. Out of the thirty-four students that participated in the survey, respondents reported that they understood SDL (97\% agree to strongly agree) and that SDL utilized during their courses was useful for clinical practice $(94 \%, N=32$ agree to strongly agree, and $6 \%$, $N=2$ somewhat agree). While all indicated that they identified and synthesized information necessary for their learning, the number of students experiencing other aspects of SDL was less (Fig. 2).

\section{Discussion}

\section{Lessons Learned Regarding the Usefulness of the Course}

Overall, the course was received positively. The students reported high levels of satisfaction and felt that the course

Table 4 Survey participants' demographics

$\%(N)$

\begin{tabular}{ll}
\hline Gender & \\
Female & $62(21)$ \\
Male & $38(13)$ \\
Race and ethnicity & \\
Asian & $12(4)$ \\
Black & $0(0)$ \\
Latinx & $12(4)$ \\
Middle Eastern & $3(1)$ \\
Native American & $0(0)$ \\
White & $68(23)$ \\
Other & $5(2)$ \\
\hline
\end{tabular}

Demographics for participants and percentage breakdowns are presented in the table 


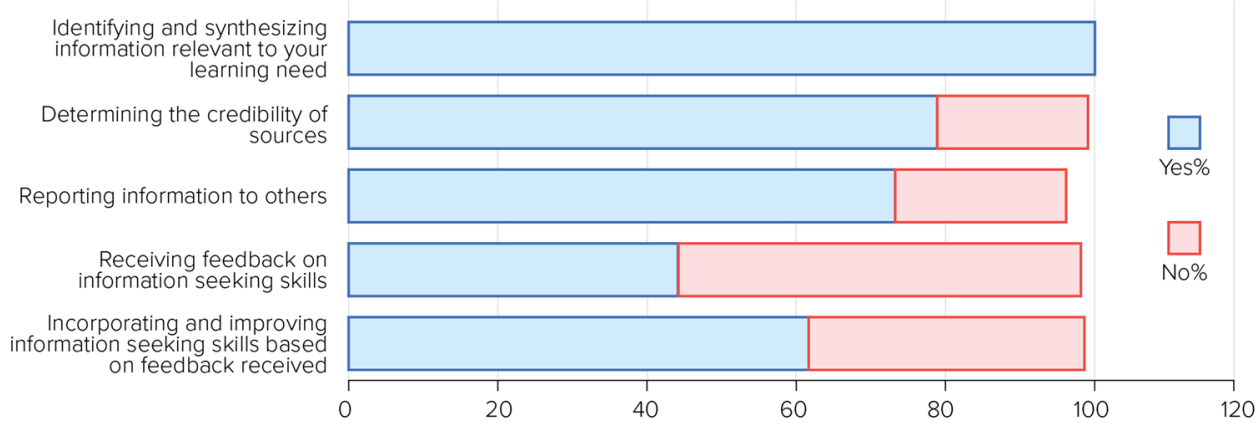

Fig. 2 Thirty-four students were asked to indicate what components of SDL they had utilized. From top to bottom, the figure shows that $100 \%$ of the students identify and synthesize information relevant to their learning, $79 \%$ of the students reported determining the credibil-

was useful for their clinical practice. This result was similar to studies exploring the use of paired collaborative SDL and/ or service opportunities to teach students about COVID$19[25,26]$. Our results are in contrast to a recent survey study that found that preclinical medical students negatively viewed e-learning [27]. It is possible that the discrepancy between the results of our case study and Sharhvini's study is the level of engagement for the students, as Sharhvini reported that a minority of students felt that there was a positive effect for participation in lecture $(23 \%)$ or problembased learning $(\sim 15 \%)$. Alternatively, the instruction on SDL mechanics that prefaced our course may have led to greater acceptance of the modality. It is also possible that the stage of the students in medical school can impact satisfaction with e-learning during this current pandemic. However, our study and other recent studies exploring the creation of student-centered electives with service or peer-teaching components indicate that this approach is useful for teaching students about an emerging disease in response to a worldwide health emergency.

\section{Lessons Learned Regarding the Course Design}

While students appreciated the course design and use of SDL, they wished there were more opportunities for students to engage in discussions. There were also two students who wished to be able to take a more passive role in their learning. SDL is a student-centered pedagogy, and learners benefit from this learning practice $[28,29]$. Therefore, we do not anticipate changing the structure to include more lectures in the future. Due to the course's 2-week limit, it was hard to incorporate more discussions and give students the time to research and design their presentations. This may be resolved by turning the course into a 4-week design. This would allow for more discussions, additional guests engagement, and more time for students to revise their work. ity of sources, $73 \%$ indicated reporting information to others, $44 \%$ reported receiving feedback on information seeking skills, and 62\% indicated incorporating and improving information-seeking skills based on feedback received

\section{Lessons Learned Regarding the Use of CSDL in the Classroom}

Moore et al. [19] describes the reciprocal relationship of CSDL and the role of peers in supporting each other's learning as thus:

CSDL relies on this reciprocal relationship wherein learners negotiate meaning and support one another through knowledge sharing, resources, and critical reflection, among other benefits. Group members, then, have a vested interest in one another. This is because they each carry the role of knowledge producer and critical reflector both for themselves and other members of the group (p. 6).

This is evident by the thematic analysis results for student reflections. Students seemed to appreciate the collaborative nature of the course, with students commenting that this allowed them to take a "deeper dive" into the material beyond what they normally would have been able to accomplish in the same time period on their own. The students demonstrated gains in general knowledge as well as knowledge and skills specifically needed for practice. Students also gained awareness in several ways. Moreover, students seemed to gain an appreciation for communication. Two of the core competencies that graduates of our program are expected to demonstrate are interprofessional collaboration and interpersonal communication skills. Therefore, we were excited to learn that participation in the course led to an appreciation for communication and collaboration. Moreover, the CSDL framework utilized in this course may be useful for promoting appreciation for interprofessional communication and collaboration and the knowledge and skills of individuals in allied health professions. Medical students have lower appreciation for interprofessional communication and collaboration as compared to other health fields [30]. Indeed, a student indicated that they would have liked to 
learn more about the pandemic from the point of view of other health professions.

I think if this were to be a continuous course that maybe even getting other people's, other healthcare professionals' perspectives on what's going on would be a really cool addition. So maybe one session would be of course the doctor but maybe another session could be a nurse or a pharmacist.

Another student in the course sought out feedback from not only medical doctors, but also nurses in order to prepare peers about the realities associated with practicing during the pandemic. In the future, we will incorporate more insight from allied health professionals.

\section{Lessons Learned Regarding Student Perceptions of SDL in the Curriculum and Its Usefulness for Practice}

While most students surveyed at our institution claimed to have understood and utilized SDL (Fig. 2), many reported that they had not utilized certain aspects of SDL. It may be that students did not explore these components of SDL in their studies. Alternatively, students may not be able to identify these components and need to be educated about the various aspects of SDL. Currently, other courses in the curriculum are initiating SDL activities in much the same fashion. It will be interesting to see if future students more readily identify as having used all of SDL components after these courses provide this form of education. Embarking on this endeavor can be difficult, but using the CSDL model as a framework for course design lends itself to this practice. We anticipate that this framework can be employed not only in clinical rotations, but also during the preclinical experiences.

Students at our institution all participate in a required scholarly concentration research program [31]. As part of this experience, students seek information related to their projects. Here, opportunities for assessing the credibility of sources, receiving feedback on all aspects of the research process, and reporting findings to others exist in the curriculum. It may be that students are not aware of the connection between these activities and the components of SDL. Here, an opportunity for helping students make connections between these activities and the implementation of SDL exists. Moreover, the CSDL framework can be employed to allow for peer-to-peer feedback and incorporation of feedback. In addition, students engage in teambased learning (TBL) and collaborative problem-based learning exercises [32]. This is also an area where there is an opportunity for utilizing and exploring components of SDL. Small group learning can increase student interest by increasing individual engagement, and therefore, the CSDL method can be applied to larger cohorts when formatted into smaller workgroups. Indeed, it has been proposed to integrate SDL in TBL in medical education to increase student learning [33].

\section{Limitations}

This case study has a number of limitations. The students that participated in this course self-selected to complete a credit requirement and, therefore, may have had a greater interest and desire to pursue the COVID-19 topic. Interest in a topic has a great influence on the success of student participation in the SDL method. Additionally, the number of students assessed for the course was small $(N=15)$ and the survey's response rate was suboptimal.

\section{Final Conclusion}

The analysis of the course evaluation and the student reflections indicate that the COVID-19/Pandemic course was useful to students. The analysis reported in the case study suggests that the CSDL framework was beneficial, including promoting awareness of the importance of SDL in their practice, basic and clinical knowledge about the subject, appreciation for collaboration with peers, and increased confidence in themselves and abilities to work in their practice. Future `studies will explore this methodology with subsequent classes and the long-term benefit of the course. Our experience with developing a virtual course using the CSDL framework could also serve as a guide for others to create similar sessions in medical education.

Abbreviations CDC: Centers for Disease Control and Prevention; CSDL: Collaborative self-directed learning; LCME: Liaison Committee on Medical Education; OU: Oakland University; OUWB: Oakland University William Beaumont; SDL: Self-directed learning; WHO: World Health Organization

Supplementary Information The online version contains supplementary material available at https://doi.org/10.1007/s40670-021-01493-7.

Acknowledgements The authors thank Rebecca Cheezem, Sarah Lerchenfeldt, Amy Smark, and Jason Wasserman for their contributions to the course; their wonderful students for participating in the course; Stephen Loftus, Tracey Taylor, Sarah Lerchenfeldt, Deidre Hurse, and Lindsay Oberleitner for editing this paper and for their feedback on this manuscript and/or data analysis; Audrey Bell for the figure designs; Tammy Tollon for blinding the transcripts for analysis; and the Oakland University William Beaumont School of Medicine for the time and resources to create this report.

Author Contribution KK, DB, and CC were involved in all aspects of the course design, data collection and analysis, and writing and editing of the paper.

Data Availability All data associated with this study are housed by the researchers on university-associated accounts and available by request in accordance with FERPA, state, and University policy. 


\section{Declarations}

Ethics Approval and Consent to Participate This work is deemed exempt research by the IRB at Oakland University (Protocol \#: IRBFY2021-342) and was done in accordance with the rules and guidance of the institution. Informed consent is not applicable.

Conflict of Interest The authors declare no competing interests.

\section{References}

1. Loeng S. Self-directed learning: a core concept in adult education. Educ Res Int Hindawi Limited. 2020.

2. Rillera Marzo R. Marzo RR. Role of medical education in cultivating lifelong learning skills for future doctors. Educ Med J [Internet]. 2018 [cited 2021 May 11];10:63. Available from: www. eduimed.com.

3. Kaufman D, Mann K. Teaching and learning in medical education: how theory can inform practice. Underst Med Educ Evidence Theory Pract. 2010. p. 164-80.

4. Garrison DR. Self-directed learning: toward a comprehensive model. Adult Educ Q [Internet]. SAGE Publications Ltd. 1997[cited 2021 May 11];48:18-33. Available from: https:// journals.sagepub.com/doi/10.1177/074171369704800103.

5. Sawatsky AP, Ratelle JT, Bonnes SL, Egginton JS, Beckman TJ. Faculty support for self-directed learning in internal medicine residency: a qualitative study using grounded theory. Acad Med [Internet]. Lippincott Williams and Wilkins. 2018[cited 2021 May 11];943-51. Available from: https://pubmed.ncbi.nlm.nih.gov/29210753/.

6. Choudhry NK, Fletcher RH, Soumerai SB. Systematic review: the relationship between clinical experience and quality of health care [Internet]. Ann Intern Med American College of Physicians. 2005[cited 2021 May 11];260-73. Available from: https://pubmed.ncbi.nlm.nih.gov/15710959/.

7. Fong SFT, Sakai DH, Kasuya RT, Kramer K, Wong VS, Haning W, et al. Medical school hotline: Liaison Committee on Medical Education Accreditation, part IV: pre-clerkship education. Hawaii J Med Public Health [Internet]. University Health Partners of Hawaii. 2016[cited 2021 May 11];75:48-51. Available from: https://hawaiijournalhealth.org/past_issues/hjmph7502_ 0048.pdf.

8. Ginzburg SB, Santen SA, Schwartzstein RM. Self-directed learning: a new look at an old concept. Med Sci Educ 2020 311 [Internet]. Springer. 2020[cited 2021 Nov 16];31:229-30. Available from: https://link.springer.com/article/10.1007/ s40670-020-01121-w.

9. Li STT, Paterniti DA, Co JPT, West DC. Successful self-directed lifelong learning in medicine: a conceptual model derived from qualitative analysis of a national survey of pediatric residents. Acad Med [Internet]. Lippincott Williams and Wilkins. 2010[cited 2021 Nov 16];85:1229-36. Available from: https://journals.lww. com/academicmedicine/Fulltext/2010/07000/Successful_Self_ Directed_Lifelong_Learning_in.30.aspx.

10. Ricotta DN, Richards JB, Atkins KM, Hayes MM, McOwen $\mathrm{K}$, Soffler MI, et al. Self-directed learning in medical education: training for a lifetime of discovery. https://doi.org/10.1080/ 1040133420211938074 [Internet]. Routledge; 2021 [cited 2021 Nov 16]; Available from: https://www.tandfonline.com/doi/abs/ 10.1080/10401334.2021.1938074.

11. Servant-Miklos V, Noordegraaf-Eelens L. Toward social-transformative education: an ontological critique of self-directed learning. Crit Stud Educ [Internet]. Routledge. 2019[cited 2021 May 11]. Available from:
https://www.tandfonline.com/action/journalInformation?journalCode= rcse20.

12. Nerali J, Telang L, Telang A, Chakravarthy PK. The role of selfdirected learning in problem-based learning: health professions education. Arch Med Heal Sci Medknow. 2016;4:125.

13. Kim S, Yang EB. Does group cohesion foster self-directed learning for medical students? A longitudinal study. BMC Med Educ [Internet]. NLM (Medline). 2020[cited 2021 May 11];20:55. Available from: https://doi.org/10.1186/s12909-020-1962-7.

14. Mentz E, Van Zyl S. The impact of cooperative learning on selfdirected learning abilities in the computer applications technology class. Int J Lifelong Educ [Internet]. Routledge. 2018[cited 2021 May 11];37:482-94. Available from: https://www.tandfonline. com/doi/abs/10.1080/02601370.2018.1513426.

15. Breed B. Exploring a cooperative learning approach to improve self-directed learning in higher education. J New Gener Sci. 2016;14:1-21.

16. Hill M, Peters M, Salvaggio M, Vinnedge J, Darden A. Implementation and evaluation of a self-directed learning activity for first-year medical students. Med Educ Online [Internet]. Taylor and Francis Ltd. 2020[cited 2021 May 11];25. Available from: https://www.tandfonline.com/doi/full/10.1080/10872981.2020. 1717780.

17. Balasooriya C, Olupeliyawa A, Iqbal MP. Innovative assessment that combines collaborative and self-directed learning with integration and application of knowledge: teamwork group projects. MedEdPORTAL [Internet]. Association of American Medical Colleges. 2016[cited 2021 May 11];12. Available from: https:// www.mededportal.org/doi/full/10.15766/mep_2374-8265.10452.

18. van Woezik TET, Koksma JJJ, Reuzel RPB, Jaarsma DC, van der Wilt GJ. There is more than 'I' in self-directed learning: an exploration of self-directed learning in teams of undergraduate students. Med Teach [Internet]. Taylor and Francis Ltd. 2021[cited 2021 Nov 16];43:590-8. Available from: https://www.tandfonline. com/doi/abs/doi.org/10.1080/0142159X.2021.1885637.

19. Moore T, Houde J, Hoggan C, Wagner J, Servage L, Fenwick T. Re-viewing adult learning: a collaborative self-directed learning model for adult educators. Adult Educ Res Conf. 2007;427-32.

20. Purdue University. Oral presentation rubric [Internet]. [cited 2021 Nov 17]. Available from: https://www.purdue.edu/science/Current_ Students/curriculum_and_degree_requirements/oral_rubrics_gray. pdf.

21. Brateanu A, Strang TM, Garber A, Mani S, Spencer A, Spevak B, et al. Using an adaptive, self-directed web-based learning module to enhance residents' medical knowledge prior to a new clinical rotation. Med Sci Educ [Internet]. Springer. 2019[cited 2021 May 25];29:779-86. Available from: https://doi.org/10.1007/ s40670-019-00772-8.

22. Keator CS, Vandre DD, Morris AM. The challenges of developing a project-based self-directed learning component for undergraduate medical education [Internet]. Med. Sci. Educ. Springer. 2016[cited 2021 May 25];801-5. Available from: www.lcme.org.

23. Lee HK, Mori C. Reflective practices and self-directed learning competencies in second language university classes. Asia Pacific J Educ [Internet]. Routledge. 2021[cited 2021 May 12];41:130-51. Available from: https://www.tandfonline.com/doi/abs/10.1080/ 02188791.2020.1772196.

24. Belgrave LL, Seide K. Grounded theory methodology: principles and practices. Handb Res Methods Heal Soc Sci [Internet]. Springer Singapore. 2019[cited 2021 May 11];299-316. Available from: https://doi.org/10.1007/978-981-10-5251-4_84.

25. Altillo BSA, Gray M, Avashia SB, Norwood A, Nelson EA, Johnston C, et al. Global health on the front lines: an innovative medical student elective combining education and service during the COVID-19 pandemic. BMC Med Educ [Internet]. BioMed 
Central Ltd. 2021[cited 2021 May 11];21:1-12. Available from: https://doi.org/10.1186/s12909-021-02616-9.

26. Elengickal JA, Delgado AM, Jain SP, Diller ER, Valli CE, Dhillon $\mathrm{KK}$, et al. Adapting education at the Medical College of Georgia at Augusta University in response to the COVID-19 pandemic: the pandemic medicine elective. Med Sci Educ [Internet]. Springer. 2021[cited 2021 May 25];31:843-50. Available from: https://doi. org/10.1007/s40670-021-01216-y.

27. Shahrvini B, Baxter SL, Coffey CS, MacDonald B V., Lander L. Pre-clinical remote undergraduate medical education during the COVID-19 pandemic: a survey study. BMC Med Educ [Internet]. BioMed Central Ltd. 2021[cited 2021 Apr 13];21:13. Available from: https://bmcmededuc.biomedcentral.com/articles/10.1186/ s12909-020-02445-2.

28. Bhandari B, Chopra D, Singh K. Self-directed learning: assessment of students' abilities and their perspective. Adv Physiol Educ [Internet]. American Physiological Society. 2020[cited 2021 May 11];44:383-6. Available from: http://advan.physiology.org.

29. Murad MH, Coto-Yglesias F, Varkey P, Prokop LJ, Murad AL. The effectiveness of self-directed learning in health professions education: a systematic review [Internet]. Med. Educ. Med Educ. 2010[cited 2021 May 11];1057-68. Available from: https://pubmed. ncbi.nlm.nih.gov/20946476/.
30. Hojat M, Ward J, Spandorfer J, Arenson C, Van Winkle LJ, Williams B. The Jefferson Scale of Attitudes Toward Interprofessional Collaboration (JeffSATIC): development and multi-institution psychometric data. J Interprof Care. 2015;29(3):238-44. https://doi.org/10.3109/ 13561820.2014.962129.

31. Sawarynski KE, Baxa DM, Folberg R. Embarking on a journey of discovery: developing transitional skill sets through a scholarly concentration program. Teach Learn Med [Internet]. Teach Learn Med. 2019[cited 2021 Nov 16];31:195-206. Available from: https://www.tandfonline.com/doi/abs/10.1080/10401334. 2018.1490184 ?journalCode $=$ htlm20.

32. Lerchenfeldt S, Ferrari T, Nyland R, Patino G. Autonomic nervous system team-based learning module. MedEdPORTAL J Teach Learn Resour [Internet]. Association of American Medical Colleges; 2016 [cited 2021 Nov 16];12. Available from: /pmc/articles/ PMC6440417/

33. Schneid SD, Lin AY, Hyderi AA. Self-directed and lifelong learning: the 5th "S" for TBL ${ }^{\mathrm{TM}}$ application exercises? Med Sci Educ [Internet]. Springer. 2019[cited 2021 Jun 2];29:1173-4. Available from: https://doi.org/10.1007/s40670-019-00783-5.

Publisher's Note Springer Nature remains neutral with regard to jurisdictional claims in published maps and institutional affiliations. 